\title{
IS IT WORTHWHILE TO PLACE BUREAUCRATESE PROCEEDINGS BY AN SME?
}

\author{
András Horváth \\ https://doi.org/10.31410/itema.2018.535
}

\begin{abstract}
During our former examinations we demonstrated a breast-wheel lifecycle model [1] for SME's. By the help of our lifecycle model we purpose to give a hand for the SMEs to compass how to handle and coordinate the general growth of their lifecycle.

Purpose of this paper is to give way to such issues in connection with the bureaucratic behaviors or interventions of an SME, which could be either foreshadowing progress or even retroactive by the day-by-day life of a company. We would like to explain, when the bureaucratic attitude of mind puts in an appearance at first by an SME from our point of view. Some other lifecycle models regard the presence of a bureaucratic period as decadence of the company on the lifecycle, but should be actually all of the bureaucratese proceedings naysayer? In the paper, we introduced some real example from a Hungarian medium-sized company's life, where the decision makers adopted some bureaucratic elements by the leading procedures. Was it worthwhile?
\end{abstract}

Keywords: bureaucratese proceeding, SME, lifecycle

\section{INTRODUCTION}

$\mathrm{T}$ The meaning and definition of bureaucracy can be interpreted and defined in almost all manner of ways; as in other scientific examinations, in the present case the interpretation depends mainly on the environment in which we perform our analyzes. Usually, in the first hearing, people involves a negative emotional relationship with the word; which is likely to be justified by the life situations arising from the social environment and the deepening of stereotypes in daily life. For example, an online concept-determining dictionary interprets the concept of bureaucratic processes as: "needlessly time-consuming processes" [2].

The moment of the appearance of bureaucratic elements is due to the increase in company size according to many people, which may be true for a non-SME corporate segment, but we can be sure that the phenomenon is by all means closely connected with the size of the company as well? In order to gain a better insight into the possible roots of problems affecting the topic, in my opinion, it is worth considering some of the related concepts that are discussed in the next chapter.

\section{RELATED PARADIGMS}

In the field of corporate lifecycle management analysis, we can see that the appearance of bureaucratic features is almost always present in the downturn phase of the corporate career. According to Adizes's model [3], one of the most well-known corporate life cycle models, early bureaucracy and bureaucracy are the first to appear in the ages of entrepreneurship.

According to Adizes "the Bureaucratic organization":

- Have many systems and rules and runs on ritual, not reason.

- Have leaders who feel little sense of control. 
- Is internally disassociated.

- Creates obstacles to reduce disruptions from its external environment.

- Forces its customers to develop elaborate approaches to bypass roadblocks." [4]

Figure 1: Bureaucracy at the Adizes Lifecycle Model [8]

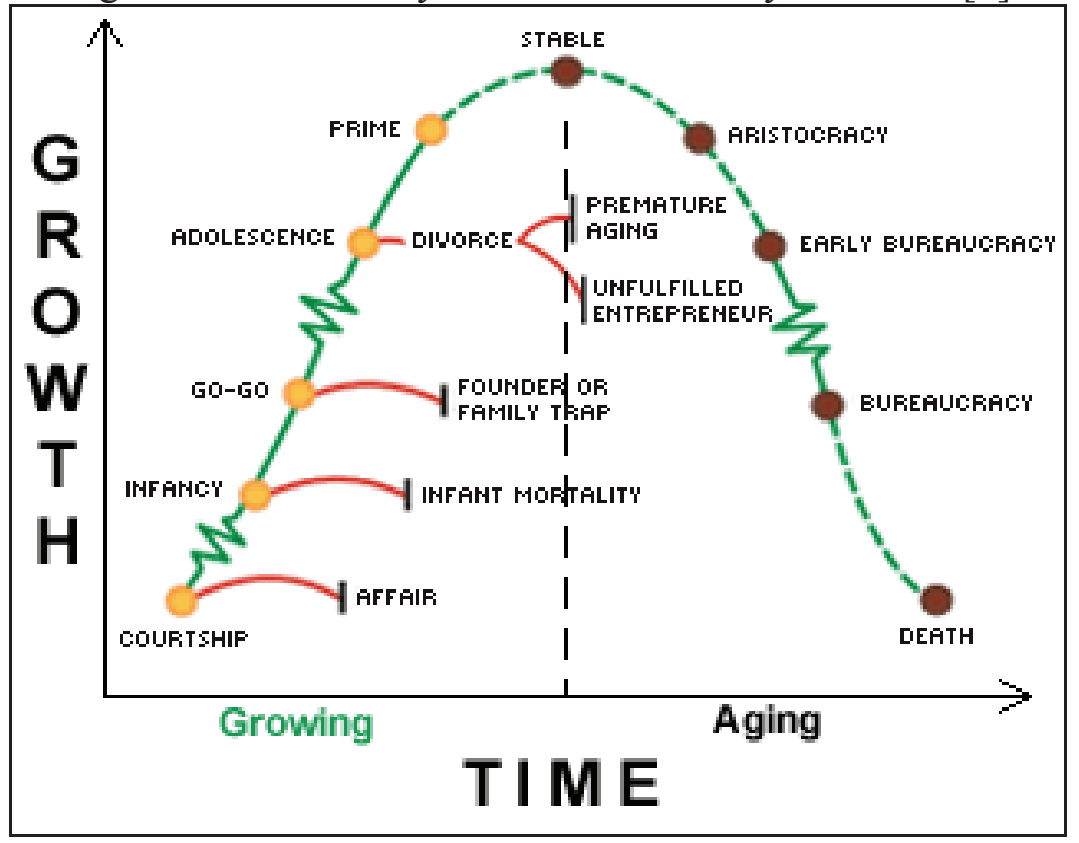

The concept of bureaucracy also appears in many other lifecycle models - as in the Greiner [5], Hisrich-Peters [6] or even de Gaus [7] models - although they no longer take a sharp stand for the features as the Adizes model.

The subject of bureaucracy is not only found in lifecycle models but also in other disciplines of management sciences, which can also be significant influencing factors. Among them, the factors to be highlighted are management styles, organizational structure, corporate communications, strategic management and strategic planning [9], external market and political environment and increasingly predictable corporate IT systems.

Considering of leadership styles, for example, the atmosphere is sharply different by a directive leadership (autocratic) business or by a participative leadership or supportive leadership [10] company. In some cases, the organizational structure predetermines the daily presence of bureaucratic features, if the individual decision-making, management or liability paths of the company are in such way designed. The corporate communications rule system can also provide a sprawling interface for bureaucratic elements; in the case of companies typically targeting formal communication channels, the number of bureaucratic functions increases in size by the size of the company. But beyond internal factors, the commitment of the external market and political environment to bureaucratic operating principles may also be decisive.

\section{EMERGENCE OF BUREAUCRATIC ELEMENTS}

After that, would you be frightened as an SME business owner if any bureaucratic attribution appears in your business life or not? In my opinion this depends on the introduction of a new concept: the level of bureaucracy. 
This level may depend on how the aforementioned management instructions and the organizational structure by the company work, and, of course, many other small but unique factors that are difficult to identify homogenously due to the diverse world of the SME sector.

As we can see, the level of bureaucracy itself is what sets the flexibility of the business itself: the relationship cannot be described either directly or inversely proportionally, but depending on how efficiently the bureaucracy is managed by the management in favor of gaining business benefits. Therefore, it is believed that the most obvious solution to balance is the use of corporate policies that are able to define standardized procedures for specific processes in certain corporate processes.

The need for continuous monitoring, as well as the need for a more complete recording of the data of individual business processes or events, is becoming increasingly important for SMEs.

Some company owners therefore identify high level of bureaucracy with the presence of high operating costs. That is why, generally, if the leader considers the level of bureaucracy to be high during some operational process, it is likely to reduce or relieve it by introducing some automation. And here comes the emergence of IT disposals as well, even among the SME sector: we can read almost every day about a revolutionary new hardware or software solution - or even an advertisement - that can provide breakthrough answer to even for our own business.

\section{BIG DATA AND BUREAUCRACY}

With increasingly emerging innovations in industry 4.0 and digital transformation, modern technology solutions are already embedded in the SME sector and can even start from technological startups. Behind the applied technologies, however, they have often bureaucratic frames: in manufacturing processes, the aim is to provide all devices and equipment with data acquisition sensors; monitoring the workflow of human resources is also a priority for maximizing efficiency and complying with production standards; the production machinery and instruments are also connected to networks, as far as possible in an automated way and communicating with each other, to provide continuous insight into every aspect of the production; as regards quality control processes, more and more measurement and test data are collected from raw material testing, including manufacturing control processes, through the full quality control of finished products; and we could still give more examples.

This results in the fact that not only multinational companies, but also the SMEs are accumulating a wealth of data, and the concept of big data also appears in their lives. The biggest challenge for SMEs is to properly select data and create targeted inventories from the big databases, that is, to decide what data can best be used for.

There is a phenomenon of controversial interest: on the one hand, the more data we collect, the more bureaucratic criteria prevail. However, with the high efficiency of the many data, we can get information that can gain competitive advantages, whether it is to increase productivity, research, or improve quality.

\section{CASE STUDIES FROM SMES}

In the following, three examples of SMEs's will be presented, where bureaucratic evolution has not come back as a retreat but has led to the emergence of positive benefits. To make the impact 
of change more transparent, each case study is presented in three phases: the preliminary state, the performed interventions and the final result.

\subsection{A CASE STUDY FROM LOGISTICS}

The preliminary state: The case study company is a 7-person SME, whose main activity is the supply of 19 liters balloon mineral water to house and businesses and the provision of water dispensing machines. The company operates close to 600 water dispensers and, on average, supplies more than 8,000 balloons of mineral water per month. Orders are recorded in a central software system, which is mainly received by phone call and online orders. The main problem is that customers cannot predict how many rechargeable empty balloons can be sent back to the new orders so the balloon storage can be difficult to trace.

The performed interventions: The Company attached NFC-tags to all of the balloons that were connected to the customers by mobile phone application on delivery of the mineral waters. The empty balloons will be scanned at all times when returned as well.

The final result: Although a new bureaucratic administrative method has been introduced, the company has an up-to-date information database on the current balloon inventory. With the help of the new system, not only stock management but customer-level consumption patterns could be measured, which could have added further benefits to the company. The NFC system's operation and manual data capture processes are very fast and economical, and because the collection of information are made by automated algorithms, the system gives almost instantaneously results for the decision-makers.

\subsection{A CASE STUDY FROM MANUFACTURING}

The preliminary state: In the present case study, there is a company with 60 employees manufacturing steel structures. There are computer-controlled (CNC) parts manufacturing machines available, but welding processes are performed by qualified welding colleagues with manual work. Workflows and work instructions are issued to so-called worksheets for physical workers. The main challenge is that the actual time requirements of the projects and the traceability of the production are very complicated if there are many simultaneous orders, and the timeliness of the related manufacturing processes is not always met.

The performed interventions: The management has placed terminals on the entire site of the plant and provided products with bar-coded product card identifiers. Physical workers also have their own bar code identifier, and the start and end times of each workflow are recorded at the terminals. For welders, a barcode registering unit was installed in each welding machine, so for them there is no need to use the terminals at all. The CNC machines have also been switched into the local network, so the operations performed on the machines are automatically recorded.

The final result: In this case, too, a number of new data capture processes, but all the operating times associated with the products, have become apparent and analyzable for the enterprise. With some automated analytical systems, there is still a way to intervene during the running production to further optimize each process. Since the data collection is also digitalized, it can be said in this case, that the amount of administrative time is dwarfed by the value of information gained by the data. 


\subsection{A CASE STUDY FROM THE FIELD OF MANAGEMENT}

The preliminary state: The third company operates with its more than 50 members on the field of production as well. With the growth of the company, the owners couldn't serve the management functions only by themselves anymore; therefore they had to open up to classical delegation solutions.

The performed interventions: The owners have set up a new corporate hierarchy system, where a business leader has been appointed. The hierarchy system was divided into groups of resource allocation and management units familiar to the multinational companies, and middle level managers were also nominated for each new group (each group consists of up to eight people). Owners manage their management and control functions through the business leader and the hierarchy system, so it is enough for them to communicate via the business leader. The business leader leads the tasks of the company's employees through regulated workflows and established standards by the occasion of the middle management meeting.

The final result: Through the introduction of the new management hierarchy system, the owners' time to acquire new business has increased. However, the speed of enterprise communication through the introduction of new bureaucratic elements (such as standards, policies, and control points) has not diminished as the flow of information through the owner, business leader and middle management axis does not interfere with any obstacle.

\section{SUMMARY}

As it can be seen from the case studies above, if newer bureaucratic elements are introduced to an enterprise at an appropriate or flexible burst level, coupled with the opportunities offered by modern facilities, they can appear not only as a retreat, but also as positive externalities during their daily business life.

Returning to the original question: is it worthwhile to place bureaucratic proceedings by an SME?

With the words of one wise teacher: it depends on... Depends on many factors. However, if the bureaucratic elements are introduced in proper time and are adequately attenuated by the possibilities of our digital world today, a number of beneficial situations can result from it.

\section{REFERENCES}

[1] Horváth, A (2016) Modern Growth Lifecycle Management Models for Micro, Small and Medium-Sized Businesses, Strategic Management, Vol. 20 (2015), No. 1, pp. 003-010, ISSN 2334-6191

[2] The Free Dictionary (2018) Online, www.thefreedictionary.com/bureaucratic+procedure (downloaded on 10.11.2018)

[3] Adizes, I. (1992) Vállalatok életciklusai. HVG Rt, Kossuth Nyomda, Budapest

[4] Adizes Institute Online, http://adizes.com/bureaucracy/ (downloaded on 11.11.2018)

[5] Greiner, Larry E. (1972) Evolution and revolution as organizations grow, Harvard Business Review, Jul-Aug, pp. 37-46.

[6] Hisrich, R. D. - Peters, M. P. (1991) Vállalkozás. Új vállalkozások indítása, fejlesztése és müködtetése, Akadémiai kiadó, Budapest.

[7] de Geus, Arie (2002) The Living Company, Harvard Business Review Press. 
[8] Figure from Online, https://bustin.com/executive-leadership-blog/business-lifecycle-getout-of-the-way/ (downloaded on 11.11.2018)

[9] Kraus, S. - Reiche, B. S. - Reschke, C. H. (2005) The role of strategic planning in SMEs: Literature review and implications, Conference proceedings of the Annual Meeting of the British Academy of Management, Oxford, UK, September 13-15.

[10] House, R.J. (1977) A 1976 theory of charismatic leadership. In J. G. Hunt, \& L. L. Larson (eds.). Leadership: the cutting edge. Carbondale, Ill: South Illinois University Press. 